potassium could occur ; thus potatoes and red beet were showing severe symptoms of potash deficiency on those plots which had had none since the experiment began, while cabbage and carrots had not yet shown any such effects. The laboratory work of this section was concerned with the biochemistry of germination and early growth and with the effect of growth-controlling substances on chemical systems.

The calculation of potential evapo-transpiration of a growing crop from meteorological data had been made possible by the work of Penman and others. The Irrigation Section was developing a practical alternative to these calculations for the commercial grower, and showed a gauge which simulated the water-balance of a plant-soil system and allowed the water deficit at any time to be read off directly. The gauge had been found to give better results than other methods currently available to growers. The section also showed experiments designed to detect the existence or otherwise of moisture-sensitive periods in vegetable crops. Such periods had been found to exist in turnips and peas, and knowledge of them was crucial to good irrigation practice.

The Weeds Section was making ecological studies on the weed seed populations in the plots of the long-term manurial and cultivation experiments, and was also studying the dormancy of weed seeds. The successful use of dinoseb (amine) as a residual preemergence herbicide for French and runner beans was demonstrated in the field, also a similar use for simazin on sweet corn.

Various aspects of their work on onions were shown by members of the Physiology Section. These included a trial of varieties for their suitability as pickling onions, and experiments on storage-temperate effects with onion varieties used for the production of sets. Fundamental work being done on competition between crop and weed was men. tioned, and members saw a field experiment on one of the practical aspects of this work, namely, the timing of early weeding in row crops. Important depressions in final yield in onions had been shown to result from relatively small delays in the first weeding date.

The Entomology Section presented results from studies on carrot fly and cabbage root fly. Existing methods for controlling carrot fly by seed-dressing followed by top sprays were expensive and sometimes gave but partial control of the pest; new methods using the incorporation of insecticides in the soil were being developed, and low rates of aldrin and dieldrin were found to give complete control of both generations for at least two years. Extensive testing had been done on the effect of soil insecticides on the flavour of carrots and had shown that dieldrin in particular produced little or no detectable changes in flavour. Assays of insecticide residues in the field had been started recently, using Drosophila; it had been found that from one application of aldrin at $2 \mathrm{lb}$. per acre four years previously an appreciable quantity still remained in the soil.

Satisfactory methods for the control of cabbage root fly by insecticides were now known, and attention was being concentrated on the ecology of the pest and the predators of its egg and larval stages. This was begun after it had been found that broadcast application of soil insecticides could lead to increased attack by cabbage root fly larve. Recent studies showed that some thirty species of insect were predators of the root fly in its early stages and that they could eat 95 per cent of the eggs laid in a season; it was these predators that were being reduced by the broadcast application of insecticides, and the situation illustrated one of the possible dangers in the indiscriminate use of insecticides in the field. Mention was also made of work on lettuce root aphid and on the control of pea moth.

The Statistics Section was concerned with all the mathematical and statistical problems arising in the work of other sections. In particular, results were being accumulated and methods developed for the analysis of plant growth data, with the object of providing more detailed interpretation of long-term field experiments.
J. A. NELDER

\title{
THE MECHANICAL ENGINEERING RESEARCH LABORATORY
}

$\mathrm{M}^{\circ}$ ORE than 1,700 visitors from industry, universities, technical colleges and other research organizations attended open days at the Mechanical Engineering Research Laboratory on June 4 and 5. All the work at East Kilbride and Thorntonhall was on show and two new laboratory buildings, completed in 1957, were open for inspection for the first time.

The Metrology Building includes a wing, with a floor area of about $6,000 \mathrm{sq}$. ft., controlled in temperature to within $\pm 0 \cdot 1^{\circ}$ of the standard temperature of $20^{\circ} \mathrm{C}$. This strict temperature control enables full advantage to be taken of the accuracy of the wide range of precision instruments available for checking the dimensional accuracy of engineering components. The metrology section provides a service to other parts of the Laboratory and to industrial firms ranging from the measurement of surface finish to the certification of the accuracy of large gear-hobbing machines. For the latter work, equipment has been developed for the autographic recording of errors in alignment between the hob. saddle motion and work-table axis of hobbing machines; errors in alignment of 0.0001 in. over a machine traverse of $5 \mathrm{ft}$. can be recorded. The Mechanisms, Engineering Metrology and Noise Control Division is also developing automatic machines for precision measurement. A prototype measuring bench has been designed for recording errors in precision lead screws: a moiré fringe technique is used and pitch errors are recorded to an accuracy of 0.0001 in. The Metrology Building also houses an anechoic chamber in which the noise-generating properties of complete machines and their component mechanisms can be measured. Preliminary tests on commercial bearings and precision bearings of the same nominal size have shown that the former were noisier, that speed was an important factor and that the radial and axial loads had no significant effect on the noise generated. 
The new Heat Building is provided with large quantities of electricity, high- and low-pressure steam, and cooling water for heat-transfer research on a substantial scale. One of the aims of the Heat Division is to provide more accurate basic design data for conventional and novel types of heat exchanger and to analyse the performance of industrial heat-exchange equipment. An experimental rig for measuring heat transfer to regenerator matrices has been used to determine the heat-transfer coefficient for the flow of air through a matrix of randomly packed steel balls. The temperature of the inlet air is varied sinusoidally so that the results are in a convenient form for mathematical analysis.

The Heat Division is also concerned with the preparation of consistent tables of the thermodynamic and transport properties of technically important fluids over wide ranges of temperature and pressure. A DEUCE computer has recently been installed, and is being used principally for this work. A start is being made with argon and carbon dioxide, and it is intended to re-calculate the steam tables and extend their range. Most of these tables will be based on existing data, but some experimental determinations of transport properties are being made. An oscillating disk method is being used to measure the viscosity of gases at moderate temperatures, at pressures up to 100 atmospheres.

The Materials Division is concerned principally with fatigue and creep of metals. It seeks, on one hand, to find out more about the stresses to which components will be subjected in service, and, on the other, to obtain a better understanding of how the material will behave under those stresses. An attempt is being made to explain the mechanism of fatigue damage and failure in terms of dislocation theory. Study of the hardening and embrittlement of mild steel caused by low-stress fatigue loading has shown that, in tensile tests subsequent to cyclic stressing, slip was confined to a few planes which had hardened during the cyclic stressing. This is difficult to account for on a random-network dislocation theory, but can readily be explained if the nature of the preparatory slip is an essential feature of the production of dislocation sources.

Measurements of the propagation of fatigue cracks in thin sheets of various metals have shown that, in the early stages, the rate of growth of a crack is proportional to the current length of crack; at very low stresses, however, non-propagating cracks may form. For fatigue tests on large components, such as railway axles, a novel electronic technique has been evolved which enables rotating-bending tests to be simulated without any rotating parts.

The Materials Division's work on creep is concerned with the behaviour of typical engineering materials under complex-stress systems. For constant loading, the relation between creep-rate, stress and time has been established for a range of metallic alloys at various working temperatures. A generalized version of this relation has now been derived for general-loading complex-stress systems, that is, those in which the stresses are varied during the course of a test. Results of these tests have been compared with various mechanical theories of creep; none of them gave predictions agreeing with the experimental data, although the age-hardening and strain-hardening theories gave upper and lower bounds, respectively. For the special case of relaxation (where the total strain remains constant) a reasonably close prediction of the complex-stress relaxation/time curves was given by the age-hardening theory for an aluminium alloy at $200^{\circ} \mathrm{C}$. and a magnesium alloy at $50^{\circ} \mathrm{C}$.

The Fluids Division is concerned with basic and applied research on mechanical engineering flow problems, particularly those occurring in waterturbines and pumps, valves, fans and compressors, and oil-pressure mechanisms. Flow measurement is essential in all hydraulic work, and improved techniques have been developed for measuring large rates of flow of liquids in pipes. Electronic equipment has been developed to record the rotational velocity of up to twenty-one propeller current-meters automatically. Advantages over conventional chart recording are convenience and the immediate indication of the number of revolutions in a pre-determ. ined time. A new integration technique has been devised for calculating total flow from point velocity readings (derived from current meters or pitot tubes) in a circular pipe; the mean velocity can be determined with at least as great an accuracy from fewer point readings than equivalent methods. Its use will save time and expense, particularly in field trials. In the salt-velocity method the mean velocity is measured by suddenly injecting into the pipeline a quantity of salt solution of higher electrical conductivity than that of the water. Its passage between two downstream positions, a known distance apart, is timed. Here again electronic techniques have been used to increase the sensitivity of the method and also to provide a direct indication of the time interval. Four flow measurement techniques, the current-meter, pitot-tube, salt-velocity and salt-dilution methods, have been tried out simultaneously in a 40 -in. diameter pipeline of a Scottish hydro-electric station at flow rates up to 70 cubic feet per second. Results from all methods agreed within \pm 2 per cent of the current-meter values, which were taken as the reference.

Research on hydraulic transmissions is also the concern of the Fluids Division. There is a growing realization in industry that the steplessly variable hydrostatic transmission provides the ideal link between an internal combustion engine and the work it has to do. A 15-h.p. pump-motor has been built with the usual reciprocating pistons replaced by reciprocating balls, resulting in an appreciable reduction in cost. It has an overall efficiency of about 80 per cent for speeds between 1,000 and 3,000 r.p.m. A 40-h.p. axial-type pump-motor has been designed, and fitted with instruments to provide basic design information on piston slipper-pads and port-plates.

The Lubrication and Wear Division undertakes experimental and theoretical investigations of the factors affecting the design and operation of all types of bearings. Gas-lubricated bearings have advantages over conventional oil-lubricated bearings for special applications. Investigations of self-acting air-bearings, where the load-carrying film is generated by hydrodynamic action, have shown that with a conventional clearance of 0.001 in., a l-in. diameter bearing can carry a load of $1 \mathrm{lb}$. per sq. in. of bearing area for each 1,000 r.p.m. Such bearings have run successfully at speeds up to 100,000 r.p.m.

A clear understanding of the processes of lubrication and wear is essential if machines are to last long enough to give an adequate return for their cost. New methods of reducing wear often depend on a better understanding of the various factors which cause it. Much attention is therefore given to 
fundamental studies of physical changes in the structure of surfaces when they are deformed by abrasion or other processes.

The manufacture of almost all metal articles involves plastic deformation of the metal. The Plasticity Division's work is directed towards providing a better understanding of the mechanism of plastic deformation so that economies in plant design and more efficient operation may be achieved. When $\alpha$-uranium is irradiated with neutrons a greatly accelerated creep takes place, even under small loads. The mathematical theory of plasticity has been applied to explain, in detail, the mechanism of this phenomenon in a uranium aggregate, starting from the known crystallographic properties of a single crystal of uranium.
In many metal-working processes the deformation takes place in the presence of hydrostatic pressure which may be considerably greater than the yield stress of the metal. Equipment has been developed for carrying out simple mechanical tests under pressure up to 100 tons per square inch. Tensile tests on various materials under a range of hydrostatic pressures have shown that there is, generally, a marked increase in their ductility as the pressure is increased. With copper, aluminium and cast-iron the increase in ductility is gradual, with zinc and 'Mazak' (a zinc-base alloy) there is an abrupt change from brittle to ductile behaviour for a small change of pressure. The possibility of extruding brittle materials by carrying out the process under high pressure is being examined. R. J. F. FrANkLIN

\section{ACCURATE MEASUREMENT OF THE VISCOSITY OF LIQUIDS}

A SYMPOSIUM on the "Accurate Measurement of the Viscosity of Liquids", arranged jointly by the Institute of Petroleum and the British Society of Rheology, was held on June 6 at the Institute of Petroleum, 61 New Cavendish St., London, W.1. It was under the chairmanship of Mr. W. Pohl (chairman of the Lubrication Committee, Institute of Petroleum) and Prof. E. G. Richardson (University of Durham, president of the British Society of Rheology).

The revised standard methods (British Standard $188: 57$ and Institute of Petroleum, $71: 58$ ) for measuring the viscosity of liquids in C.G.s. units, which incorporate the experience and the results of co-operative experimental work obtained in Britain and other countries during the post-war years, describe a 'stepup' procedure for the calibration of glass capillary-type viscometers, using master viscometers and freshly distilled water at $20 \cdot 00^{\circ} \mathrm{C}$. with an agreed viscosity of 1.002 centipoises ( 1.0038 centistokes). Dr. R. Roscoe (University of Durham) pointed out in a paper on the determination of viscosity by the oscillating vessel method that further research on accurate absolute methods of viscosity measurement of liquids as standards is desirable, because of the difficulty in the capillary tube method of the elimination of the end correction. The slight inconsistencies in the careful measurements of J. F. Swindells, J. R. Coe and T. B. Godfrey, who found the viscosity of water at $20.00^{\circ} \mathrm{C}$. to be $1.0019 \pm 0.0003 \mathrm{cP}$., arise from small differences in the ends of paired tubes. The oscillating vessel method, advocated by Prof. Andrade and A. Chiong, may prove to be better for accurate viscosity measurements. Dr. Roscoe described a series of precise measurements with water, using oscillating vessels, both spherical and cylindrical, supported by a graduated capillary tube so that the water acted as its own thermometer. In this preliminary work a value obtained for the coefficient of viscosity for water at $20^{\circ} \mathrm{C}$. was $1.0025 \pm 0.0005$, but an analysis of the sources of error in the results suggests that with fairly simple improvements in technique, for example, using cylindrical vessels and measuring angular velocity rather than amplitude of oscillation, the accuracy of the method, of the order one part in 10,000 , could be substantially greater than that obtained in capillary tube measurements.

The measurement of viscosity by means of a vibrating system using an electronic counting technique was described by Mr. M. T. Browne (Imperial College and Queen Elizabeth College, London), who gave the method of calculating viscosity values for water from the logarithmic decrement, the electronic apparatus counting the number of cycles of vibration occurring while the amplitude decreases from one value to half this value.

For oils of higher viscosity the liquid is located on a plane end of the rod. The apparatus is particularly adapted to measure small changes of viscosity.

In a paper on the precise measurement of kinematic viscosity in the petroleum industry, K. A. Lammiman and P. P. Morris (Esso Research Ltd.) described standard instruments and modern equipment involving electronic timing devices, precisely controlled thermostat baths for a temperature-range from $-100^{\circ}$ to $200^{\circ} \mathrm{C}$. and above, and the technique used for the scrupulous cleaning of instruments by pressure jets of solvents. The authors described methods of measuring viscosity when only small amounts were available; these required the use of the standard miniature British Standard viscometers, torque viscometers such as the plate-cone type, vibrating systems and a comparative method of the rate of descent of an index of oil $(0.05 \mathrm{ml}$.) in an inclined capillary.

Methods of examining opaque oils and fuel oils and their heat pretreatment were also described, as well as semi-automatic methods using viscometers fitted with platinum probes at the fiduciary markings.

During the past two decades industry has become 'shear' conscious mainly in connexion with the requirements of the Armed Services and the automotive industry. At the rates of shear occurring during flow in standard viscometers, the viscosity does not show variations, but at high rates of shear the coefficient of viscosity is no longer a constant. Dr. $R$. Schnurmann (Esso Research Ltd.) described a jet viscometer in which frictional heating is practically eliminated when a liquid is forced slowly and in individual drops through a narrow streamlined constriction.

By varying the pressure difference across the aperture or the temperature the rate of shear can be altered over a wide range. The kinetic energy correction can be determined experimentally and is smaller by a factor of 2 than for long capillary viscometers, which usually have a length to diameter ratio of 100 . 